\title{
File sharing as conditional cooperation: evidence from a framed field experiment
}

\section{Wojciech Hardy, Michal Krawczyk \& Joanna Tyrowicz}

To cite this article: Wojciech Hardy, Michal Krawczyk \& Joanna Tyrowicz (2018): File sharing as conditional cooperation: evidence from a framed field experiment, Applied Economics Letters, DOI: 10.1080/13504851.2018.1441494

To link to this article: https://doi.org/10.1080/13504851.2018.1441494

\section{Published online: 22 Feb 2018.}

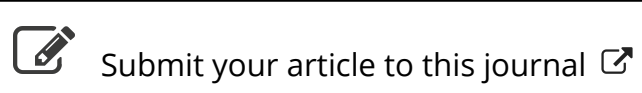

\section{Цll Article views: 1}

Q View related articles ¿

View Crossmark data $\asymp$ 


\title{
File sharing as conditional cooperation: evidence from a framed field experiment
}

\author{
Wojciech Hardy ${ }^{\mathrm{a}, \mathrm{b}}$, Michal Krawczyk ${ }^{\mathrm{a}, \mathrm{c}}$ and Joanna Tyrowicz $\mathbb{1}^{c, \mathrm{~d}, \mathrm{e}, \mathrm{f}}$ \\ aFaculty of Economics, University of Warsaw, Warsaw, Poland; 'bnstitute for Structural Research; 'FAME|GRAPE, Warsaw, Poland; ${ }^{\text {bFaculty }}$ of

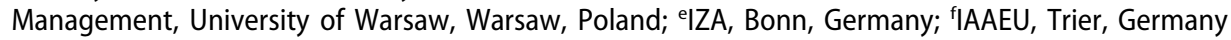

ABSTRACT

In this project, we investigate downloading and sharing behaviour in a novel 'piracy game' modelled after standard public good games. We find that willingness to share correlates positively with the sharing by others. By contrast, actual behaviour in the 'piracy game' is not correlated with self-reported behaviour.
KEYWORDS

Digital piracy; public goods; laboratory experiment; file-sharing; reciprocity

JEL CLASSIFICATION C92; D63; Z1

\section{Introduction}

Peer-to-Peer (P2P) networks are one of the main channels used to obtain pirated content online. They only work effectively if copies of files already in the network are freely shared and new ones are regularly uploaded. As a result, various mechanisms promoting active participation and/or punishing freeriding have been proposed and built into the network architecture (Feldman and Chuang 2005). There are also informal sanctions, e.g. downloaders are referred to as leechers within the torrenting community.

Despite the importance of reciprocity norms among digital pirates, they have hardly been studied. We fill this gap by providing evidence from a framed field experiment (Harrison and List 2004) with natural stimuli: student subjects play a stylized 'piracy game' with (conditional) cooperation in the context of file sharing.

We contribute to the existing literature in three ways. First, we establish that file-sharing behaviour is reciprocal: engagement is conditional on the actions of others. Second, we find that the self-reported measures or 'piracy' that dominate the literature ${ }^{1}$ are a poor predictor of actual sharing decisions. Third, unlike previous framed field experiments with adult subjects, we use nonmonetary stimuli. ${ }^{2}$

\section{Design and procedures}

We ran a computerized laboratory experiment consisting of four parts, one of which had been preselected to determine earnings of the participants on top of the show-up fee of 5 PLN ( $\approx 1.20$ euro). The parts comprised

(1) 'a piracy game', in which subjects revealed their willingness to share content on the Internet;

(2) valuation, eliciting the individual pricing of online transfer;

(3) a version of Holt and Laury (2002) task to reveal risk aversion;

(4) a version of Charness and Rabin (2002) task to reveal social preferences.

In the first two parts, the participants could earn the right to download content from Poland's most popular file-sharing service Chomikuj.pl. It is known for hosting files that are shared without the copyright owners' consent. Each account on Chomikuj.pl can collect the so-called transfer (e.g. through direct purchase) that amounts to the number of MBs a user can download.

'The Piracy game' is built as an analogy to public good games, a common way for operationalizing dilemmas of conditional cooperation in experimental economics. We used the one-shot strategy method

CONTACT Joanna Tyrowicz j.tyrowicz@uw.edu.pl

${ }^{1}$ E.g. Selwyn (2008); Morris and Higgins (2008); Wingrove, Korpas and Weisz (2011).

${ }^{2}$ Studies with children include Harbaugh and Krause (2000); Alencar, Deoliveirasiqueira and Yamamoto (2008); overall, little is known on how public good games generalize to other reward domains.

6 Supplemental data for this article can be accessed here.

○ 2018 Informa UK Limited, trading as Taylor \& Francis Group 


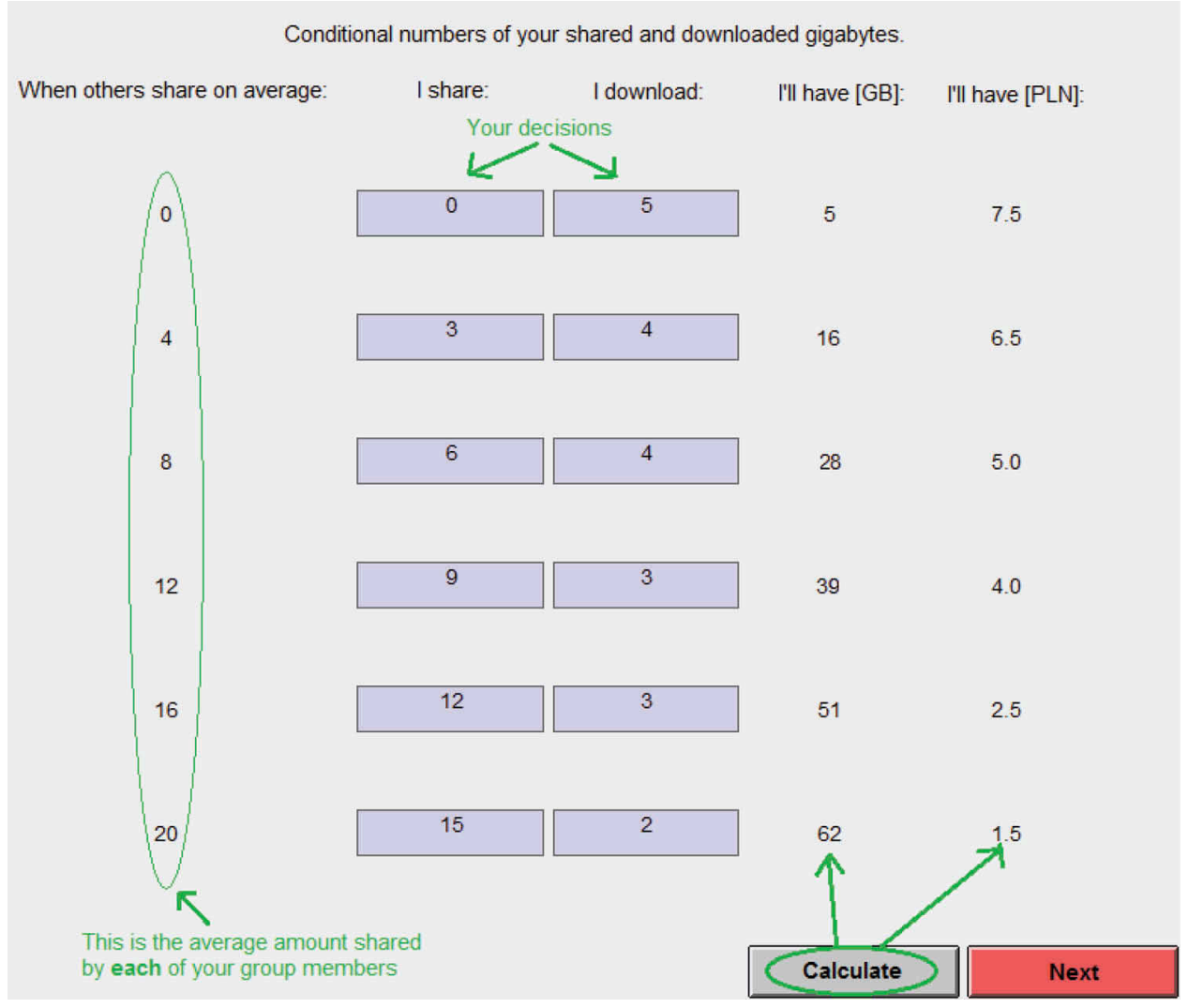

Figure 1. A decision screen in the 'piracy game', as presented in the printed instructions. Instruction elements were only displayed on the instruction screen.

approach of Fischbacher, Gächter and Fehr (2001). Subjects were randomly and anonymously matched into groups of four and informed that the final outcome would depend on their decisions along with the decisions of other group members. Subjects were endowed with 10 PLN and could spend any amount up to that limit on 'downloading' and 'sharing'. The price of $1 \mathrm{~GB}$ was 0.5 PLN (e.g. they could download 10 GB, share 5 GB and keep 2.50 PLN in cash). Subjects were informed that each GB downloaded would increase the amount of data transfer allocated to his or her Chomikuj.pl account, should this part be randomly selected for determining their final compensation. Likewise, sharing $1 \mathrm{~GB}$ would benefit the account of each of the other group members by $1 \mathrm{~GB}$.

Subjects made both unconditional and conditional sharing decisions, both types being incentivized. Unconditional decisions had to be made without any knowledge of what other group members could choose. Conditional decisions were choices contingent on how much other group members were sharing on average, see Figure 1. To assist subjects, the screen with the conditional decisions was equipped with a calculator (subjects saw how their individual, conditional choices translated to monetary payment and transfer rights). Subjects were also asked to provide a (nonincentivized) prediction of other participants' mean contribution.

A 'Valuation' of Chomikuj.pl data transfer (first 10 GB and then $20 \mathrm{~GB}$ ) was performed using iterative multiple price lists (Andersen et al., 2006). We report the mean of the two resulting valuations of $1 \mathrm{~GB}$, accurate to one decimal place. For example, if someone was willing to pay 10 PLN for 10 GB and 16.2 PLN for $20 \mathrm{~GB}$, then the inferred value of $1 \mathrm{~GB}$ would be 9 PLN.

\section{Other characteristics and self-evaluation}

Subjects' risk-aversion was elicited using the method of Holt and Laury (2002). Their social preference was elicited using the method of Charness and Rabin (2002). ${ }^{3}$ Big Five personality traits of the participants were elicited as in Laguna et al. (2014).

\footnotetext{
${ }^{3}$ Their design was modified to capture differences between deliberate and instinctive choices, following Dyrkacz and Krawczyk (2015).
} 
Table 1. 'The Piracy' game results and self-reported behaviour.

\begin{tabular}{|c|c|c|c|c|c|c|}
\hline & \multicolumn{4}{|c|}{ Self-reported status } & \multirow[b]{2}{*}{ Total } & \multirow[b]{2}{*}{ Kruskal-Wallis $p$-value } \\
\hline & Nonpirates & Occasional leechers & Frequent leechers & Seeders & & \\
\hline GB valuation & 0.42 & 0.58 & 0.57 & 0.59 & 0.56 & 0.19 \\
\hline \multicolumn{7}{|c|}{ Unconditional decisions } \\
\hline Download (GB) & 2.34 & 3.72 & 3.00 & 3.83 & 3.51 & 0.18 \\
\hline Share (GB) & 1.39 & 2.91 & 3.74 & 2.90 & 2.80 & 0.20 \\
\hline Belief about sharing & 4.12 & 4.10 & 3.74 & 3.95 & 4.04 & 0.70 \\
\hline \multicolumn{7}{|c|}{ Classification based on Fischbacher, Gächter and Fehr (2001) } \\
\hline Conditional cooperators & $38 \%$ & $49 \%$ & $47 \%$ & $54 \%$ & $48 \%$ & \\
\hline Unconditional cooperators & $8 \%$ & $14 \%$ & $0 \%$ & $5 \%$ & $10 \%$ & \\
\hline Free-riders & $54 \%$ & $37 \%$ & $53 \%$ & $41 \%$ & $42 \%$ & \\
\hline No. of participants & 26 & 127 & 19 & 40 & 212 & \\
\hline
\end{tabular}

Notes: For the Kruskal-Wallis test, we report the $p$-value for a null hypothesis that all four groups are drawn from the same population. The unconditional decision to download and share refers to the variant of the piracy game when the sharing decisions of the others are not known. Belief about sharing is the belief on how many GBs the others will share with the group. Details of Fischbacher, Gächter and Fehr's (2001) classification are reported in the online Appendix.

Subjects self-reported their frequency of file sharing and downloading from various legitimate and unauthorized sources. ${ }^{4}$ They also filled in their gender, education and income status. Details of the design can be found in the online Appendix.

The experiment was run at the Laboratory of Experimental Economics in Warsaw in 13 sessions, between 24 January 2015 and 19 March 2015. It was computerized using zTree (Fischbacher 2007). There were 212 participants in total. Around $80 \%$ of them were students (about half of whom majored in economics) and 58\% were female.

\section{Results}

Subjects were generally interested in purchasing transfer for themselves and willing to share nontrivial amounts for others, with means of 3.51 and 2.80 $\mathrm{GB}$, respectively. Twenty-six per cent of participants never wanted to download and $28 \%$ never wanted to share $(19 \%$ never wanted either). Following Fischbacher, Gächter and Fehr (2001), for each subject we run a separate regression of the sharing choice conditional on the others' sharing behaviour. This provided us with an individual-specific measure of reciprocity in the Piracy game. We distinguish three types: free-riders, unconditional cooperators and conditional cooperators. ${ }^{5}$ The distribution of types is largely consistent with the findings of Fischbacher, Gächter and Fehr (2001): 48\% are conditional cooperators, $42 \%$ are free-riders and only $10 \%$ are unconditional cooperators.
Using subjects' self-evaluation, we distinguish nonpirates (never download or upload copyrighted material), occasional leechers (download sometimes and never share), frequent leechers (often download and never share) and seeders (admit to sharing). Table 1 provides the cross-tabulation of self-reported and observed behaviour, demonstrating these are nearly independent. Self-reported 'piracy' behaviour does not correlate either with unconditional sharing in the 'piracy' game or with the valuation of data transfer.

Higher valuation of data transfer is associated with higher levels of sharing, see hurdle estimations in Table 2. The coefficient representing the impact of others' sharing on own sharing is estimated very robustly at .5 , implying that for each 1 GB of received data transfer (equivalent to roughly one movie in low quality), our subjects were willing to share a half of it (equivalent to roughly one and half episodes of a TV series in low quality). The impact of personality traits is quite weak, with conscientious individuals being less likely to share at all and emotionally stable individuals being both more likely to share at all and more likely to share larger amounts of data. This appears natural given how this trait is defined (Lounsbury and Gibson 2006, so long as file sharing is a stressful rule-violating activity). The negative link between conscientiousness and deviant behaviours seems robust in the literature, while the findings for emotional stability seem more mixed (e.g. Salgado 2002; Karim, Zamzuri, and Nor 2009; Swami, Chamorro-Premuzic, and Furnham 2009).

\footnotetext{
${ }^{4}$ We gave subjects some examples of the most popular websites within each category

${ }^{5}$ See online Appendix for details of the procedure.
} 


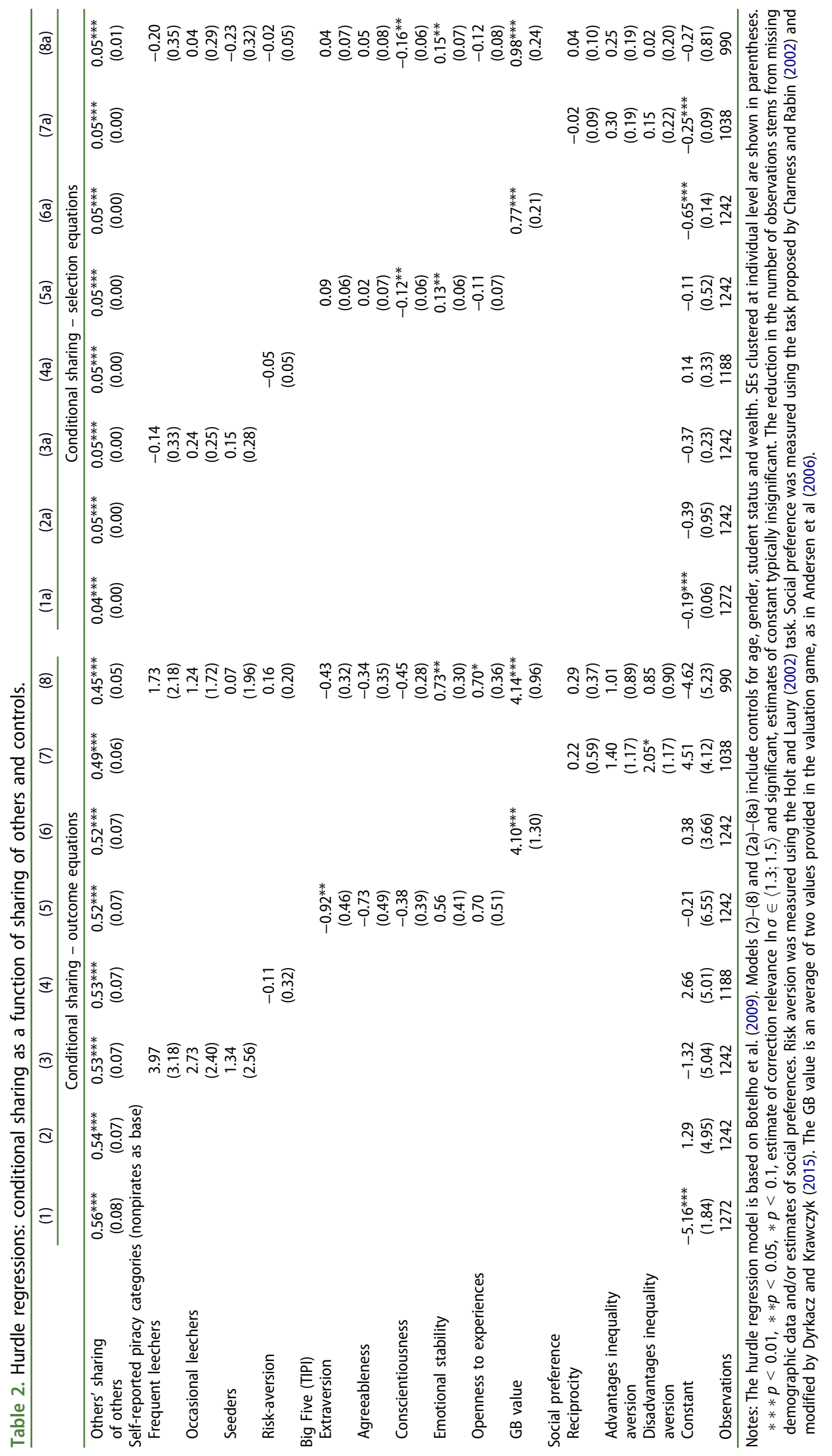


Table 3. Hurdle regressions of conditional sharing on sharing of others, by self-reported behaviour groups.

\begin{tabular}{|c|c|c|c|c|}
\hline & (1) Nonpirates & (2) Occasional leechers & (3) Frequent leechers & (4) Seeders \\
\hline \multicolumn{5}{|c|}{ Outcome equations } \\
\hline $\begin{array}{l}\text { Sharing } \\
\text { of others }\end{array}$ & $\begin{array}{l}0.58^{*} \\
(0.30)\end{array}$ & $\begin{array}{c}0.45^{* * *} \\
(0.08)\end{array}$ & $\begin{array}{c}0.53^{* * *} \\
(0.11)\end{array}$ & $\begin{array}{l}0.65^{* * *} \\
(0.15)\end{array}$ \\
\hline \multicolumn{5}{|c|}{ Selection equations } \\
\hline $\begin{array}{l}\text { Sharing } \\
\text { of others }\end{array}$ & $\begin{array}{l}0.04^{* * *} \\
(0.01)\end{array}$ & $\begin{array}{l}0.04^{* * *} \\
(0.01)\end{array}$ & $\begin{array}{l}0.05^{* * *} \\
(0.01)\end{array}$ & $\begin{array}{l}0.05^{* * *} \\
(0.01)\end{array}$ \\
\hline Observations & 114 & 156 & 762 & 240 \\
\hline
\end{tabular}

The measures of risk aversion and social preference seem to have no impact.

To see if the relationship between the sharing of other participants and own propensity to share depends on own real-life experiences, we repeat the previous specification separately for each category of self-reported behaviour, see Table 3. Because the sample sizes are much smaller, we only include two of the base control variables: gender and age. The file-sharing reciprocity estimates remain significant and positive for all subgroups and for both equations. Moreover, their magnitude is similar to that reported in Table 2 (with only the coefficient in the seeders group being slightly larger than in other specifications). These results support the notion that reciprocity may be a major factor inducing people to share content, even if they are not actually prone to file-sharing behaviour and have no previous 'piracy' experience. One reason for that is many of them have peers who are involved in file sharing, so they are well acquainted with the activity, which is likely to affect their own attitudes and behaviours (Cox, Collins, and Drinkwater 2010). Thus, while our sample is not representative the entire online population, the results may hold for all relevant types of internet users.

\section{Conclusions}

We find file sharing to be a case for conditional cooperation. This makes our findings valuable beyond the audience interested in determinants of Internet piracy. Indeed, so far, economists running incentivized experiments on reciprocity invariably considered monetary contributions and payments. We demonstrate that reciprocal behaviours generalize to other domains that can be conveniently studied in the lab.
Identifying the reciprocal nature of file sharing also allows to draw from the rich literature on conditional cooperation. Specifically, we can look for suggestions for possibly effective policy measures. This literature typically seeks instruments fostering cooperation, such as framing of the situation, manipulating beliefs about others' sharing, introducing communication between agents and using informal sanctions for freeriding. These, among others, could be thus fruitfully used by either P2P platforms or to curb the scope of unauthorized file sharing. For example, allowing chat function fosters conditional cooperation, thus it is likely to encourage more sharing. Moreover, if file sharers hold a false-consensus belief that everybody shares, dispelling this myth may restrain their propensity to share.

We also find evidence that sharing and downloading is associated with higher valuation of the transfer rights for downloading cultural goods (music, films and books), implying that 'pirates' are in principle willing to pay more for such goods. Consequently, some of the 'pirates' could possibly be converted into customers if they were presented with sufficiently attractive prices and distribution channels.

Finally, judging by our sample, self-reports on piracy behaviour are not reliable. While subjects knew they were being observed (they could adjust their behaviour to what they perceived as 'appropriate') if anything, it should strengthen the correlation with self-evaluation which are likely subject to the same type of self-censoring. Likewise, the abstract measures of risk aversion and social preference (reciprocity included) were not predictive. We thus postulate that piracy research should more often reach for dedicated, behavioural tasks, such as the 'piracy' game we have proposed. 


\section{Acknowledgements}

We would like to thank Marta Dyrkacz and Katarzyna Pfeifer for their help with the experiment set-up. Anna Kukla-Gryz and the participants of the GRAPE seminar provided valuable feedback. All errors are ours.

\section{Disclosure statement}

No potential conflict of interest was reported by the authors.

\section{Funding}

The financial support from the National Science Centre under grant number: [UMO-2011/01/D/HS4/03937] is gratefully acknowledged.

\section{ORCID}

Joanna Tyrowicz (D) http://orcid.org/0000-0002-5928-332X

\section{References}

Alencar, A. I., J. de Oliveira Siqueira, and M. E. Yamamoto. 2008. "Does Group Size Matter? Cheating and Cooperation in Brazilian School Children." Evolution and Human Behavior 29 (1): 42-48. doi:10.1016/j. evolhumbehav.2007.09.001.

Andersen, S., G. W. Harrison, M. I. Lau, and E. E. Rutström. 2006. "Elicitation Using Multiple Price List Formats." Experimental Economics 9 (4): 383-405. doi:10.1007/ s10683-006-7055-6.

Botelho, A., G. W. Harrison, L. M. Costa Pinto, and E. E. Rutström. 2009. "Testing Static Game Theory with Dynamic Experiments: A Case Study of Public Goods.” Games and Economic Behavior 67 (1): 253-265. doi:10.1016/j.geb.2008.11.013.

Charness, G., and M. Rabin. 2002. "Understanding Social Preferences with Simple Tests." The Quarterly Journal of Economics 117: 817-869. doi:10.1162/ 003355302760193904.

Cox, J., A. Collins, and S. Drinkwater. 2010. “Seeders, Leechers and Social Norms: Evidence from the Market for Illicit Digital Downloading." Information Economics and Policy 22: 299-305. doi:10.1016/j.infoecopol.2010.09.004.

Dyrkacz, M., and M. Krawczyk. 2015. "Exploring the Role of Deliberation Time in Non-Selfish Behaviour: The Double Response Method." Working Papers 2015-27. Faculty of Economic Sciences, Warszawa: University of Warszawa.

Feldman, M., and J. Chuang. 2005. "Overcoming Free-Riding Behavior in Peer-To-Peer Systems." ACM SIGecom Exchanges 5 (4): 41-50. doi:10.1145/1120717.
Fischbacher, U. 2007. "z-Tree: Zurich Toolbox for ReadyMade Economic Experiments." Experimental Economics 10 (2): 171-178. doi:10.1007/s10683-006-9159-4.

Fischbacher, U., S. Gächter, and E. Fehr. 2001. “Are People Conditionally Cooperative? Evidence from a Public Goods Experiment." Economics Letters 71 (3): 397-404. doi:10.1016/S0165-1765(01)00394-9.

Harbaugh, W. T., and K. Krause. 2000. "Children's Altruism in Public Good and Dictator Experiments." Economic Inquiry 38 (1): 95-109. doi:10.1111/ ecin.2000.38.issue-1.

Harrison, G. W., and J. A. List. 2004. "Field Experiments." Journal of Economic Literature 42: 1009-1055. doi:10.1257/0022051043004577.

Holt, C. A., and S. K. Laury. 2002. "Risk Aversion and Incentive Effects." American Economic Review 92 (5): 1644-1655. doi:10.1257/000282802762024700.

Karim, N., N. H. A. Zamzuri, and Y. M. Nor. 2009. "Exploring the Relationship between Internet Ethics in University Students and the Big Five Model of Personality." Computers \& Education 53 (1): 86-93. doi:10.1016/j.compedu.2009.01.001.

Laguna, M., W. Bak, E. Purc, E. Mielniczuk, and P. Oles. 2014. "Short Measure of Personality TIPI-P in a Polish Sample." Roczniki Psychologiczne 17 (2): 421-437.

Lounsbury, J. W., and L. W. Gibson. 2006. Personal Style Inventory: A Personality Measurement System for Work and School Settings. Knoxville, TN: Resource Associates.

Morris, R. G., and G. E. Higgins. 2008. "Neutralizing Potential and Self-Reported Digital Piracy: A MultiTheoretical Exploration among College Undergraduates." Criminal Justice Review, 34(2): 173-195.

Salgado, J. F. 2002. "The Big Five Personality Dimensions and Counterproductive Behaviors." International Journal of Selection and Assessment 10 (1-2): 117-125. doi:10.1111/ijsa.2002.10.issue-1\&2.

Selten, R. 1965. "Spieltheoretische Behandlung Eines Oligopolmodells Mit Nachfrageträgheit: Teil I: Bestimmung Des Dynamischen Preisgleichgewichts." Zeitschrift für die gesamte Staatswissenschaft/Journal of Institutional and Theoretical Economics, no. H2: 301-324.

Selwyn, N. 2008. "A Safe Haven for Misbehaving? An Investigation of Online Misbehavior among University Students." Social Science Computer Review 26 (4): 446465. doi:10.1177/0894439307313515.

Swami, V., T. Chamorro-Premuzic, and A. Furnham. 2009. "Faking It: Personality and Individual Difference Predictors of Willingness to Buy Counterfeit Goods." The Journal of Socio-Economics 38 (5): 820-825. doi:10.1016/j.socec.2009.03.014.

Wingrove, T., A. L. Korpas, and V. Weisz. 2011. "Why Were Millions of People Not Obeying the Law? Motivational Influences on Non-Compliance with the Law in the Case of Music Piracy." Psychology, Crime \& Law 17 (3): 261276. doi:10.1080/10683160903179526. 